\title{
Dynamic QTL analysis for developmental behavior of cell wall components and forage digestibility in maize (Zea mays L.)
}

Kun Li

Institute of Crop Sciences, Chinese Academy of Agricultural Sciences

Xue Yang

Institute of Crop Sciences, Chinese Academy of Agricultural Sciences

Xiaogang Liu

Institute of Crop Sciences, Chinese Academy of Agricultural Sciences

Xiaojiao Hu

Institute of Crop Sciences, Chinese Academy of Agricultural Sciences

Yujin Wu

Institute of Crop Sciences, Chinese Academy of Agricultural Sciences

Qi Wang

Institute of Crop Sciences, Chinese Academy of Agricultural Sciences

Feiqian Ma

Institute of Crop Sciences, Chinese Academy of Agricultural Sciences

Shuqiang Li

Institute of Crop Sciences, Chinese Academy of Agricultural Sciences

Hongwu Wang

Institute of Crop Sciences, Chinese Academy of Agricultural Sciences

Zhifang Liu

Institute of Crop Sciences, Chinese Academy of Agricultural Sciences

Changling Huang ( $\nabla$ huangchangling@caas.cn )

Institute of Crop Sciences, Chinese Academy of Agricultural Sciences

\section{Research Article}

Keywords: Quantitative trait locus, Maize (Zea mays L.), Cell Wall Components, Forage quality

Posted Date: December 17th, 2020

DOI: https://doi.org/10.21203/rs.3.rs-128172/v1 
License: (c) (i) This work is licensed under a Creative Commons Attribution 4.0 International License. Read Full License 


\section{Dynamic QTL analysis for developmental behavior of cell}

2 wall components and forage digestibility in maize (Zea mays

3 L.)

4 Kun $\mathrm{Li}^{1,2, \#}$, Xue Yang ${ }^{1,2, \#}$, Xiaogang Liu ${ }^{1,2}$, Xiaojiao $\mathrm{Hu}^{1,2}$, Yujin $\mathrm{Wu}^{1,2}$, Qi Wang ${ }^{1,2}$,

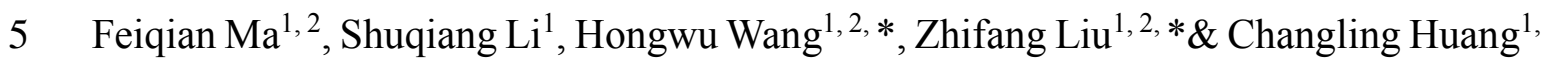

$62, *$

$7 \quad{ }^{1}$ Institute of Crop Sciences, Chinese Academy of Agricultural Sciences, Beijing, China.

$8 \quad{ }^{2}$ National Engineering Laboratory for Crop Molecular Breeding, Beijing, China.

$9 \quad$ \#Equal contributors

10 Correspondence:

11 *Hongwu Wang

12 wanghongwu@caas.cn

13 *Zhifang Liu

14 liuzhifang@caas.cn

$15 *$ Changling Huang

16 huangchangling@caas.cn 


\section{Abstract}

\section{Background}

19 Cell wall architecture plays a key role in stalk strength and forage digestibility. Lignin,

20 cellulose and hemicellulose are the three main components of the plant cell wall and

21 can impact stalk quality by affecting cell wall structure and strength. To explore cell

22 wall development during secondary cell wall lignification in maize stalks, conventional

23 and conditional genetic mappings was used to identify the dynamic quantitative trait 24 locus (QTL) for cell wall components and digestibility traits in five growth stages after 25 silking.

\section{Results}

Acid detergent lignin (ADL), cellulose (CEL), Acid detergent fiber (ADF), neutral detergent fiber (NDF), and in vitro dry matter digestibility (IVDMD) of stalk were evaluated in a maize recombinant inbred line (RIL) population. The cell wall components gradually increased in the 10-40 days after silking (DAS), reached a maximum at 30-40 DAS, and then steadily decreased. IVDMD decreased over the initial 40 DAS and then increased slightly. Seventy-two QTL were identified for five traits and each accounted for $3.48-24.04 \%$ of the phenotypic resistance variation.

34 Twenty-six conditional QTL were detected using conditional QTL mapping. 22 out of

3524 conditional QTL were found for stages III|II and V|IV. Six QTL hotspots were found

36 localized in bins 1.08, 2.04, 2.07, 7.03, 8.05, and 9.03 in the maize genome.

\section{Conclusion}

The unconditional pleiotropic QTL in bins 1.08 and 8.05 were also associated with stalk strength. Furthermore, several pleiotropic QTL for cell wall and digestibility were 
found not associated with stalk strength. A simultaneous improvement in forage

41 digestibility and lodging resistance can be achieved by pyramiding multiple effective QTL identified in the present study.

Keywords: Quantitative trait locus, Maize (Zea mays L.), Cell Wall Components,

Forage quality.

\section{Background}

Maize (Zea mays L.) can be bio-refined to provide sustainable bioproducts and bioenergy [1]. More importantly, the stover of this staple crop is usually treated as a significant feed resource for ruminant animal production in China. The cell walls of maize plants not only provide mechanical tissues for structure support and protection but also determine feeding value by affecting forage digestibility. Plant cell walls consist of cellulose, which is Earth's most abundant organic compound; lignin, the world's most abundant resource of bio-aromatics; and hemicelluloses (xylan and glucomannan) [2]. Lignin contributes the most to resistance to digestion [3]. Lignin has a variable decreasing effect on degradation because of changes in content in the cell wall, its variable structure, and how it binds to other cell wall components [4]. Given that the forage quality is a complex and integrated trait that can be affected by many factors, breeders are inclined to improve forage quality by using integrated or digestibility traits, such as NDF, ADF, and IVDMD.

In addition to the efforts made to improve the forage quality of silage maize, several studies were performed to dissect the genetic architecture of forage digestibility and related traits. With the development of molecular biology and genetics, researchers are eager to know the genetic correlation between cell wall components and forage digestibility and mine elite resources and genes to improve the digestibility of silage maize. As an alternative strategy, mutants that induce high cell wall digestibility can be 
used in silage maize breeding for feeding value; mutants are also ideal genetic material for mining genes that codify cell wall biosynthesis. Brown midrib $(\mathrm{bm})$ mutant plants accumulate reddish-brown pigmentation in the leaf midrib and stalk. These mutants have significantly reduced lignin content and/or high cell wall digestibility [5]. To date, six $b m$ mutants have been identified in maize. The $b m 1, b m 2, b m 3$, and $b m 4$ loci encode cinnamyl alcohol dehydrogenase, methylenetetrahydrofolate reductase, caffeic acid $O$ methyltransferase, and folylpolyglutamate synthase, respectively [6-10]. These genes are associated with lignin biosynthesis and the upstream monolignol pathway. Furthermore, the $b m 5$ mutation has been mapped in bin 5.04 and encode 4-coumarate: coenzyme A ligase $[11,12]$. By fine mapping, bm6 was finally mapped to a $180 \mathrm{~kb}$ region on chromosome 2 [13].

Because of its excellent performance in increasing silage intake and milk production, the $b m 3$ mutant has been widely used in cell wall digestibility and feeding value improvements in commercial hybrids. Comparisons of normal and $b m 3$ silage hybrids have revealed the powerful effect of $b m 3$ on improving feeding value and cell wall digestibility [14]. However, $b m$ mutants are associated with a reduction in dry matter yield and changes in days to flowering [15], as well as stress tolerance including lodging, drought, pest, and disease [14]. Therefore, one of the key strategies to improve silage maize with $\mathrm{bm}$ mutants is to find the appropriate balance between feeding value and agronomic traits.

In addition to mutant utilization in silage maize breeding, studies have been performed to dissect the genetic basis of cell wall-related traits and silage quality by using quantitative genetic approaches. Besides major mutations, QTL with small effects contribute to genetic variation of forage digestibility. Several studies have been carried out to detect QTL for cell wall composition and digestibility traits [16-29], and four hotspots of QTL were found located in bins 2.08, 5.03, 6.04, and 9.06 [30]. To summarize the QTL information, a meta-analysis was performed on the results of these 
studies, and eight highlighted regions of meta-QTL for both digestibility and cell wall traits were identified [31]. The genetic variation of digestibility and cell wall-related traits are, thus, controlled by several major effect loci and numerous minor effect QTL that are distributed over the maize genome. Although numerous QTL have been identified for cell wall and digestibility related traits, few have been used in markerassisted breeding programs. Moreover, because cell wall biosynthesis is the result of a dynamic process that consists of physiological and biochemical changes, a genetic analysis of cell wall and digestibility traits might not provide a reasonable explanation for forage quality. In this study, a maize RIL population was used to investigate the genetic relationships between cell wall compositions and digestibility traits. The objectives were to (1) identify the dynamic QTL related to cell wall composition and digestibility by using conventional and conditional mapping methods and (2) dissect the genetic basis of the cell wall components and digestibility in maize.

\section{Materials and methods}

\section{Development of the RIL population and field experiments}

An RIL population consisting of 215 lines was developed using the single seed descent method from an elite hybrid Zhongdan909. The parental lines of this commercial hybrid are Zheng58, which is one of the most commonly used parental lines in China, and HD568. All $F_{10}$ RILs and the two parental lines were planted in 2012, in the Winter Nursery Farm of the Chinese Academy of Crop Sciences (Sanya, $109^{\circ} 10^{\prime} \mathrm{E}, 18^{\circ} 21^{\prime} \mathrm{N}$ ), a famous winter nursery located in southern China. The genetic materials were planted in 2013 in the Agronomy Farm of the Chinese Academy of Crop Sciences (Beijing $\left.116^{\circ} 34^{\prime} \mathrm{E}, 39^{\circ} 54^{\prime} \mathrm{N}\right)$. The field experimental design followed an incomplete block design approach, with two replications at each location. Each line was grown in a single $2.5 \mathrm{~m}$ row with $0.67 \mathrm{~m}$ between rows and a planting density of 45,000 plants/ha. 
118 The silking date was recorded when $50 \%$ of the silks emerged from all plants in each

119 line. The 2nd-5th internodes above the ground from six plants of each line were 120 collected using garden shears at 10, 20, 30, 40, and 50 DAS, respectively. All samples

121 were immediately enzyme-deactivated at $105^{\circ} \mathrm{C}$ for $30 \mathrm{~min}$ and air-dried for $10-14$ days.

122 Dried stalk samples were ground using an automatic hammer mill herb grinder and

123 filtered through a screen with a mesh size of $0.1 \mathrm{~mm}$. Before measurements, the stalk

124 samples were dried at $45^{\circ} \mathrm{C}$ for $48 \mathrm{~h}$ to exclude the influence of moisture. CEL, ADL, 125 ADF, NDF, and IVDMD were estimated using near-infrared reflectance spectroscopy.

126 The samples were scanned using a near-infrared reflectance spectrophotometer (Vector

127 22/N, Bruker Optik, Ettlingen, Germany). A modified partial least squares approach 128 implemented in OPUS 6.0 Bruker software was used to fit the calibration equations.

129 The coefficients of determination for cross-validation $\left(\mathrm{R}_{c v}^{2}\right)$ ranged from $90.2 \%$

130 (IVDMD) to $94.0 \%$ (CEL), and the coefficients of external validation $\left(\mathrm{R}_{v a l}^{2}\right)$ were $92.7 \%$

131 for ADL, $96.7 \%$ for CEL, $94.6 \%$ for ADF, $96.5 \%$ for NDF, and 91.2\% for IVDMD.

\section{Phenotypic data analyses}

133 A mixed linear model implemented with the "Imer" function in the "Ime4" package in $134 \mathrm{R}$ version 3.6.0 ( $\mathrm{R}$ development Core Team, 2019) was fitted to calculate the best linear 135 unbiased prediction (BLUP) value for each line: $y_{i}=\mu+g_{i}+e_{i}+\varepsilon_{i}$, where $y_{i}$ 136 represents the phenotype of the "i"th line, $\mu$ is the grand mean value of the target trait 137 in all environments, $g_{i}$ represents the genetic effect, $e_{i}$ is the environmental effect 138 (replications in each environment were also treated as environmental effects in the 139 BLUP mixed model), and $\varepsilon_{i}$ is the random error. The grand mean was fitted as a fixed 140 effect, and genotype and environment were considered as random effects. The 141 estimated BLUP was denoted as the sum of the grand mean and genetic effects of each 142 line. The BLUP values of each line were used as phenotypic values for QTL mapping. 
A standard analysis of variance was conducted using the base "aov" function in R. The model used for the analysis of variance was $y_{i l k}=\mu+e_{l}+r_{k(l)}+f_{i}+$ $(f e)_{i l}+\varepsilon_{i l k}$, where $e_{l}$ is the environmental effect of the "l"th environment, $r_{k(l)}$ is the effect of replications within environments, $f_{i}$ represents the genetic effect of the "i"th line, $(f e)_{i l}$ is the interaction effect between genetic and environment effects, and $\varepsilon_{i l k}$ is the residual error. All the effects were considered as random effects. Broad-sense heritability was calculated as $H^{2}=\sigma_{g}^{2} /\left(\sigma_{g}^{2}+\sigma_{g e}^{2} / e+\sigma_{\varepsilon}^{2} / r e\right)$, where $\sigma_{g}^{2}$ represents the genetic variance, $\sigma_{g e}^{2}$ is the variance of interaction between the genotype and environment, $\sigma_{\varepsilon}^{2}$ is the residual error variance item, and $e$ and $r$ are the number of environments and replications in each environment, respectively. The $95 \%$ confidence intervals of $H^{2}$ were calculated following the method of Knapp et al. [32].

\section{Genotyping and genetic map construction}

Leaf tissues were collected from all 215 RILs and their parental lines and freeze-dried at $-60^{\circ} \mathrm{C}$. Genomic DNA was extracted using the modified CTAB method [33] and used for genotyping with the maize 55K single-nucleotide polymorphism (SNP) array [34]. The quality of each SNP was manually controlled as described by Yan et al. [35], and SNPs with poor quality were excluded from further analysis. PLINK [36] was used to estimate the minor allele frequency (MAF), missing rate, and heterozygosity for each $\mathrm{SNP}$, as well as the missing rate and heterozygosity for each line. After quality control, SNPs with a missing rate $\leq 20 \%$, heterozygosity $\leq 10 \%$, and MAFs $\geq 0.05$ were used to construct the genetic linkage map; 14,544 SNPs were used in constructing the genetic map for the RIL population. Finally, the genetic bin map of $1519.5 \mathrm{cM}$ was constructed using ASMap for R [37], and map distances were calculated using the Kosambi mapping function [38].

\section{QTL mapping}

BLUP values across environments were used in QTL mapping of the cell wall 
components and digestibility traits. A whole-genome scan was performed using composite interval mapping ( $\mathrm{cim}$ ) implemented in the R package $R /$ qtl (version 1.44-9) [39]. A test with 1,000 permutations was performed to generate the logarithm of odds (LOD) significance threshold, which was set at $\alpha<0.05$ [40]. The confidence intervals for the locations of the QTL were determined via 1.5-LOD support intervals to each side of the position of the maximum LOD.

In addition to the unconditional QTL mapping, dynamic conditional QTL mapping was performed using the composite interval mapping method. Conditional phenotypic values were the cell wall component trait values in adjacent stages, which represent the extra genetic effect, $\Delta \mathrm{G}$, between the genetic effect at stage $t\left(\mathrm{G}_{(t)}\right)$ and that at stage $\mathrm{t}-1$ $\left(\mathrm{G}_{(t-1)}\right)$. The conditional phenotypic values $\mathrm{y}_{(\mathrm{t} t \mathrm{t}-1)}$ were obtained by the mixed model implemented in QGAStation 2.0 (http:/ibi.zju.edu.cn/software/qga/) [41] and were subsequently treated as unconditional phenotypic values to perform composite interval mapping with the $\mathrm{R} / \mathrm{qtl}$ package.

\section{Results}

\section{Phenotypic variation and correlation between traits}

Each line of the RIL population was sampled at five stages, including 10-50 DAS (denoted as stages I, II, III, IV, and V), and evaluated for CEL, ADL, ADF, NDF, and IVDMD. For convenience, the phenotypic value of each trait at each stage was denoted as "Trait_Stage." For example, "ADF_I" represents the ADF measured at stage I. The cell wall components and digestibility traits were evaluated in five stages and two environments in the present study. The phenotypic values of ADF, NDF, CEL, and ADL in Zheng58 were slightly lower than those in HD568 at stage I, nearly equal to those in HD568 at stage II, and surprisingly surpassed those in HD568 at stages III and IV. At the final stage, the values of these traits in Zheng58 showed a significant decrease, and they were lower than those in HD568. For the RIL population, the average IVDMD 
195

196 four traits displayed a completely opposite tendency (Figure 1). The variation of each 197 trait at various stages ranged from 1.21- (NDF_V) to 1.94-fold (IVDMD_IV).

198 Meanwhile, the variation of each trait increased over the first four stages and decreased 199 in the last stage (Figure 1). IVDMD, which ranged from -0.61 to -0.96 , was negatively 200 correlated with the other four traits in each corresponding stage. In addition, the ADF, 201 NDF, CEL, and ADL showed high and positive correlations with each other across all 202 stages (Figure 2). The results of the variance analysis showed that the cell wall 203 components and digestibility of the maize stem were significantly affected by the 204 genotype, environment, and interactions between the genotype and environment. The 205 broad-sense heritability of the traits ranged from 0.47 (IVDMD_V) to 0.72 (ADF_I) 206 (Table 1).

\section{Unconditional QTL mapping}

After 1,000 permutation tests, the empirical threshold LOD values for the genome-wide significance $(\mathrm{p}<0.05)$ were determined, ranging from 3.8 to 4.1 for various stages and traits. A total of 72 unconditionally detected QTL for cell wall components and digestibility traits at five sampling stages were identified on nine chromosomes. The percentage of trait variation explained by each QTL ranged from $3.48 \%$ to $24.04 \%$. Approximately $22.2 \%(16 / 72)$ QTL accounted for more than $10 \%$ of the phenotypic variation.

For ADF, 14 QTL were detected on chromosomes 1, 2, 4, 7, 8, and 9 at the five stages, individually explaining $5.20-13.48 \%$ of the phenotypic variance (Table 2). Among these QTL, two major effect QTL were detected on chromosomes 2 and 9. On chromosome 1, a QTL located at 201.5-207.8 cM was detected at multiple stages (stages I, II, and IV) and was responsible for $6.67 \%, 7.01 \%$, and $6.25 \%$ of the phenotypic variance, respectively. Additionally, another consensus QTL located at $90.7-92.8 \mathrm{cM}$ on chromosome 2 was found to be responsible for $13.48 \%, 12.13 \%$, and 
$5.56 \%$ of the phenotypic variance at stages I, II, and III, respectively. Moreover, two overlapping QTL were detected at $62-66 \mathrm{cM}$ and $42-45 \mathrm{cM}$ on chromosomes 7 and 9, respectively.

For NDF, 16 QTL were detected on chromosomes 1, 2, 7, 8, and 9. Each QTL could explain $3.48-13.97 \%$ of the total phenotypic variance at different stages. Thirteen of the NDF-related QTL overlapped and formed four consensus QTL clusters. These hotspot loci were distributed at 202.7-20.35 cM on chromosome $1,90.6-92.8 \mathrm{cM}$ on chromosome 2, 65.3-71.4 cM on chromosome 7, and 43.1-45.2 cM on chromosome 9. Twelve unconditional QTL for ADL were identified during the five development stages. Among these, 11 QTL were distributed on chromosomes 1, 2, and 6. Similar to that for ADF, the QTL located at $201.3-207.8 \mathrm{cM}$ on chromosome 1 were identified for ADL at stages I and II. During stages I, II, and V, two consensus QTL related to ADL were found at $140.7-141.2 \mathrm{cM}$ on chromosome 2 and $20.7-21.3 \mathrm{cM}$ on chromosome 6 . Moreover, the overlapped QTL on chromosome 2 contributed to $24.04 \%, 15.18 \%$, and $16.11 \%$ of the phenotypic variance at stages I, II, and V, respectively, which seems to be a stable and major effect QTL for ADL.

During the five stages, 11 unconditional QTL for CEL were detected. These QTL were distributed on chromosomes 1, 2, 6, and 7 (Table 2, Figure 3). Each QTL could explain $5.12-18.97 \%$ of the total variance. The QTL located at $91.1-92.8 \mathrm{cM}$ on chromosome 2 was repeatedly detected at stages I, II, III, and IV and contributed to $5.42-18.97 \%$ of the total phenotypic variance.

For IVDMD, 19 QTL were detected on eight chromosomes. Among these, 12 overlapping QTL were integrated into four consensus QTL. Among these overlapping QTL, four were identified repeatedly at $202.7-207.8 \mathrm{cM}$ on chromosome 1 . These QTL contributed to $6.66 \%, 12.99 \%, 6.76 \%$, and $5.81 \%$ of the total phenotypic variance at stages II, III, IV, and V, respectively. In addition, the QTL located at approximately 92.0-92.8 cM on chromosome 2 was correlated with IVDMD at stages I, II, and III. On chromosome 9, the QTL at 43.1-46.0 cM was identified to be strongly related to 
250 IVDMD at stages I, II, and V. Moreover, another overlapping QTL for IVDMD was 251 detected on chromosome 10, which was located at 49.5-50.2 cM and contributed to $2525.07 \%$ and $8.16 \%$ of the total phenotypic variance at stages I and V, respectively.

\section{Conditional QTL mapping}

254 In total, 26 conditional QTL were identified at five stages for cell wall components and 255 digestibility traits (Table 3). Each QTL could explain 1.02-14.95\% of the phenotypic 256 variance. All the conditional QTL were detected on eight chromosomes, except for 257 chromosomes 4 and 8. Approximately 61.5\% (16/26) QTL were distributed on 258 chromosomes 1 and 2.

259 Five ADF-related conditional QTL were identified as distributed on chromosomes $2601,2,3$, and 6 . When the ADF at stage $\mathrm{V}$ was conditioned on the ADF at stage IV, 261 conqADF1b and conqADF2 were detected on chromosomes 1 and 2; these QTL were 262 responsible for $10.15 \%$ and $11.99 \%$ of the total variance, respectively. At the IV|III 263 stage, conqADF1a and conqADF3 were found to contribute to $1.02 \%$ and $3.89 \%$ of the 264 total variance, respectively. On chromosome 6, conqADF6 was detected with a contribution of $5.40 \%$ when the $\mathrm{ADF}$ at stage III was conditioned on the ADF at stage II. conqADL1a and conqADL1b overlapped the QTL located on chromosome 1 and contributed to $5.34 \%$ and $7.98 \%$ of the total variance for ADL at the IV|III and V|IV stages, respectively. In addition to that on chromosome 1, a conditional QTL on

271 chromosome 2, conqADL2, was detected when the ADL at stage V was conditioned on 272 the ADL at stage IV. This major effect QTL could explain $13.41 \%$ of the total variance. 273 Moreover, at stage III|II, conqADL10 was identified to be responsible for $4.84 \%$ of the 274 total variance.

275 For CEL, five conditional QTL were found at stages III|II, IV|III, and V|IV. At 276 stages IV|III and V|IV, QTL conqCEL1a and conqCEL1b were located at adjacent 
positions on chromosome 1 and contributed to $3.93 \%$ and $10.70 \%$ to the total variance,

278 respectively. Another major conditional QTL at the V|IV stage located on chromosome

2792 was conqCEL2 and contributed to $14.95 \%$ of the total variance. When the CEL at 280 stage III was conditioned on the CEL at stage II, conqCEL5 and conqCEL7 were 281 identified on chromosomes 5 and 7.

282 Conditional QTL mapping for IVDMD revealed six QTL on chromosomes 1, 2, 6, 283 9, and 10. These conditional QTL were identified at the III|II and V|IV stages. When 284 the IVDMD at stage III was conditioned on the IVDMD at stage II, QTL 285 conqIVDMD1a, conqIVDMD2, and conqIVDMD6 were responsible for $6.39 \%, 6.06 \%$, 286 and $5.21 \%$ of the total variance, respectively. In addition, QTL conqIVDMDIb, 287 conqIVDMD9, and conqIVDMD10 identified at stage $\mathrm{V} \mid \mathrm{IV}$, could explain $8.68 \%$, $2889.08 \%$, and $7.67 \%$ of the total variance in the IVDMD.

289 Similar to that for the IVDMD, six conditional QTL were identified for NDF. All 290 these QTL were also found at stages III|II and V|IV. Moreover, three conditional QTL 291 for NDF detected at stage III|II overlapped with the conditional QTL for IVDMD 292 detected at the same stage (conqIVDMD1a, conqIVDMD2, and conqIVDMD6). At 293 stage V|IV, three conditional QTL conqNDF1b, conqNDF2b, and conqNDF9 294 contributed to $9.00 \%, 6.91 \%$, and $10.12 \%$ of the total variance in the NDF. conqNDF $1 b$ 295 was found to be overlapped with conqIVDMDIb, which was identified at stage V|IV 296 for IVDMD.

\section{Discussion}

298 The area of maize in China has been expanding annually. The livestock industry 299 requires large amounts of silage maize owing to the increase in demand for meat and 300 milk. However, common maize is still the main variety promoted in China because of 301 the policy of self-sufficiency in food production. Although silage maize has a large 302 amount of biomass, higher than that of common maize, its starch and dry matter content 303 is lower than that of common maize. Therefore, silage made of grain and forage maize 
varieties is more popular in China. The critical issue is that the choice of harvesting time is a trade-off among yield, feeding value, and silage quality.

Lodging is a critical phenomenon for maize production, causing severe yield reduction during the reproductive stage. Stronger cell walls can provide more powerful mechanical support to avoid lodging. By contrast, cell wall digestibility, which is strongly affected by cell wall lignification, is a vital characteristic for the nutritional value of forage maize [42]. Cell wall lignification is a dynamic and complex process that occurs throughout maize growth. In the present study, we used a maize RIL population to investigate the dynamic changes in cell wall component and digestibility traits at five stages from silking to harvest. For each trait, no apparent differences were observed among the beginning stages. ADF, NDF, ADL, and CEL showed a massive increase at stages III and IV and exhibited a slight decrease at stage V. Conversely, IVDMD showed a large decrease at stages III and IV and exhibited a small increase at stage V. This inverse trend may be associated with significant negative correlations between these traits and IVDMD. These results revealed that the optimal harvest time for grain-forage maize was approximately 50 DAS. At this time, the plant has reached physiological maturity and the grain is in full dent stage. After harvesting for grain, the plant can also be harvested for forage or stover to feed animals. Alternatively, forage maize could be harvested between stages II and III, which is roughly in the dough stage. During this period, starch has just begun accumulating in the grains, and plant digestibility decreases slightly. Forage harvested at this stage can provide sufficient nutritional value and ensure silage quality.

Cell wall components mainly consist of cellulose, lignin, and hemicellulose. NDF mainly consists of cellulose, hemicelluloses, lignin, and some mineral substances present in the cell wall [25]. After hemicelluloses are solubilized by acid detergent treatment, the residual cellulose and lignin are left as the main part of ADF [31]. In maize, previous studies on cell wall components and digestibility traits have focused on specific stages $[16,20,22-27,29,30,43,44]$, such as 10-14 DAS and the silage 
332 harvest stage (approximately $30-35 \%$ of dry matter). QTL detected at these specific 333 stages may not reflect the genetic effects of crop development. In the present study, to 334 better understand the developmental characteristics of cell-wall components, we 335 performed dynamic QTL analysis during five developmental stages after silking.

336 As there was no significant difference among the phenotypic values of stages I and 337 II, no conditional QTL was found for any of the traits when stage II was conditioned on 338 stage I. Moreover, several overlapping unconditional QTL were detected between these 339 two stages. In general, unconditional QTL hotspots were located on chromosomes 1, 2, 3407,8 , and 9. The co-localized QTL on chromosome 1 was located in bin 1.08, which 341 corresponded to the $215-250 \mathrm{Mb}$ physical region in the maize genome (Version 5.60) 342 [45]. This genomic region was also detected as a meta-QTL hotspot for cell wall content 343 and digestibility [31]. Moreover, this locus was shown to be associated with stalk 344 strength in another study [38] in which QTL mapping was performed for rind 345 penetrometer resistance (RPR) using the same RIL population that was used in the 346 present study. We found that another pleiotropic QTL for RPR was associated with ADF, 347 NDF, and IVDMD. This pleiotropic QTL was localized in bin 8.05 and explained 6.61$34814.06 \%$ of the phenotypic variance for each trait. Therefore, this major effect QTL 349 should be the target for fine mapping and gene cloning.

350 In addition to the pleiotropic QTL mentioned above, we detected several 351 pleiotropic QTL for cell wall and digestibility; however, these were not associated with 352 RPR. On chromosome 2, a co-localized QTL in bin 2.07 was found to be related to CEL 353 and ADL at various stages. Another overlapped QTL in bin 2.04 was repeatedly 354 detected for all four traits except ADL. Thus, we concluded that a cellulose synthesis 355 gene is responsible for the genetic variation at this locus. Another overlapping QTL 356 region was found on chromosome 7. At stage III, this QTL located in bin 7.03 was 357 detected for all five traits. A hotspot QTL on chromosome 9 was associated with ADF, 358 NDF, and IVDMD, which means that this QTL may affect plant digestibility by 359 affecting cell wall components other than cellulose and lignin. All these cell wall and 
digestibility QTL hotspots should be the focus of attention for further cloning of candidate genes and favorable alleles. The genes underlying these QTL should be responsible for secondary cell wall digestibility but not affect cell wall rigidity. In this context, it is possible to improve the digestibility of silage through molecular markerassisted modification of these QTL without reducing stalk strength. Furthermore, a simultaneous improvement in forage digestibility and lodging resistance can be achieved by pyramiding multiple effective genes underlying all the pleiotropic QTL.

Most conditional QTL were mainly detected for stages III|II and V|IV owing to the significant phenotypic differences between the two adjacent stages. Six out of 26 conditional QTL explained more than $10 \%$ of the phenotypic variation for each trait. Compared with the results of unconditional mapping, conditional mapping revealed a few novel QTL. Remarkably, the genomic region in bin 1.02 was related to five traits under conditional stages and was responsible for $8.00-10.70 \%$ of the phenotypic variation. Comparatively, we verified that the pleiotropic QTL in bin 2.07 was consistently identified by both conditional and unconditional QTL mapping. These results revealed that the combination of genes expressed stably at different periods and the genes expressed only at specific periods lead to the dynamic development of cell wall components. Therefore, the application of multi-omics approaches in future studies will help to better understand the dynamic development of cell wall components and their genetic regulatory mechanisms.

In summary, we evaluated cell wall components and digestibility in multiple developmental stages after silking and revealed the law of dynamic changes in an RIL population. We identified 72 and 26 consensus QTL using unconditional and conditional QTL mapping, respectively. Our study highlighted six regions (localized in bins $1.08,2.04,2.07,7.03,8.05$, and 9.03) that were of particular interest. Some of these showed pleiotropic effects on digestibility and stalk strength in maize, whereas the others could be applied to improve forage digestibility without altering lodging resistance. These findings enhance our understanding of the genetic mechanism of 
maize cell wall synthesis.

\section{Abbreviations}

ADF: Acid detergent fiber; ADL: Acid detergent lignin; BLUP: Best linear unbiased prediction; CEL: cellulose; DAS: days after silking; IVDMD: in vitro dry matter

392 digestibility; LOD: Logarithm of odds; NDF: Neutral detergent fiber; MAF: minor 393 allele frequency; QTL: Quantitative trait locus/loci; RIL: recombinant inbred line; SNP: 394 Single nucleotide polymorphism.

\section{Reference}

1. Scholey DV, Burton EJ, Williams PEV: The bio refinery; producing feed and fuel from grain. Food Chem 2016, 197(Pt A):937.

2. Zhong R, Cui D, Ye Z-H: Secondary cell wall biosynthesis. New Phytol 2019, 221(4):1703-1723.

3. Argillier $\mathrm{O}$, Barrière $\mathrm{Y}$, Hébert $\mathrm{Y}$ : Genetic variation and selection criterion for digestibility traits of forage maize. Euphytica 1995, 82(2):175-184.

5. Barrière $Y$, Ralph J, Méchin V, Guillaumie $S$, Grabber JH, Argillier $\mathrm{O}$, Chabbert B, Lapierre C: Genetic and molecular basis of grass cell wall biosynthesis and degradability. II. Lessons from brown-midrib mutants. CR Biol 2004, 327(9-10):847-860.

6. Vignols $F$, Rigau J, Torres MA, Capellades $M$, Puigdomènech $P$ : The brown midrib3 (bm3) mutation in maize occurs in the gene encoding caffeic acid O-methyltransferase. Plant Cell 1995, 7(4):407-416.

7. Chen W, VanOpdorp N, Fitzl D, Tewari J, Friedemann P, Greene T, Thompson S, Kumpatla S, Zheng $\mathrm{P}$ : Transposon insertion in a cinnamyl alcohol dehydrogenase gene is responsible for a brown midrib1 mutation in maize. Plant Mol Biol 2012, 80(3):289-297.

8. Tang HM, Liu S, Hill-Skinner S, Wu W, Reed D, Yeh CT, Nettleton D, Schnable PS: The maize brown midrib2 (bm2) gene encodes a methylenetetrahydrofolate reductase that contributes to lignin accumulation. Plant $J$ 2014, 77(3):380-392.

9. Li L, Hill-Skinner S, Liu S, Beuchle D, Tang HM, Yeh CT, Nettleton D, Schnable PS: The maize brown midrib4 (bm4) gene encodes a functional folylpolyglutamate synthase. Plant $J$ 2015,

419 10. Halpin C, Holt K, Chojecki J, Oliver D, Chabbert B, Monties B, Edwards K, Barakate A, Foxon GA: 
Plant J 1998, 14(5):545-553.

422 11. Haney L, Hake S, Scott M: Allelism testing of Maize Coop Stock Center lines containing unknown brown midrib alleles. Maize Genetics Cooperative Newsletter 2008, 82.

12. Xiong W, Wu Z, Liu Y, Li Y, Su K, Bai Z, Guo S, Hu Z, Zhang Z, Bao Y et al: Mutation of 4-coumarate:

14. Barrière $Y$ : Brown-midrib genes in maize and their efficiency in dairy cow feeding. Perspectives for breeding improved silage maize targeting gene modifications in the monolignol and p-hydroxycinnamate pathways. Maydica 2017, 62(2017):M21. coenzyme $A$ ligase 1 gene affects lignin biosynthesis and increases the cell wall digestibility in maize brown midrib5 mutants. Biotechnol Biofuels 2019, 12:82.

13. Chen $Y$, Liu H, Ali F, Scott MP, Ji Q, Frei UK, Lubberstedt T: Genetic and physical fine mapping of the novel brown midrib gene bm6 in maize (Zea mays L.) to a $180 \mathrm{~kb}$ region on chromosome 2. Theor Appl Genet 2012, 125(6):1223-1235.

17. Lübberstedt T, Melchinger AE, Schön CC, Utz HF, Klein D: QTL mapping in testcrosses of

18. Bohn M, Schulz B, Kreps R, Klein D, Melchinger A: QTL mapping for resistance against the European corn borer (Ostrinia nubilalis $\mathrm{H}_{\text {.) }}$ in early maturing European dent germplasm. Theor Appl Genet 2000, 101(5-6):907-917. European flint lines of maize: I. Comparison of different testers for forage yield traits. Crop Sci 1997, 37(3):921-931. Barriere Y, Gibelin C, Argillier O, Mechin V: Genetic analysis in recombinant inbred lines of early dent forage maize. I: QTL mapping for yield, earliness, starch and crude protein contents from per se value and top cross experiments. Maydica 2001, 46(4):253-266. and QTL mapping of cell wall digestibility and lignification in silage maize. Crop Sci 2001, 41(3):690-697. European corn borer (Ostrinia nubilalis $\mathrm{Hb}$.) in early maturing European dent maize (Zea mays L.) germplasm and comparison of genomic regions for resistance across two populations of $\mathrm{F3}$ families. Maydica 2001, 46(3):195-205. Roussel V, Gibelin C, Fontaine A, Barriere Y: Genetic analysis in recombinant inbred lines of early dent forage maize. II. QTL mapping for cell wall constituents and cell wall digestibility from per se value and top cross experiments. Maydica 2002, 47(1):9-20. fiber and lignin content in maize. Theor Appl Genet 2003, 106(5):866-874.

4. Fontaine A, Briand M, Barriere Y: Genetic variation and QTL mapping of para-coumaric and ferulic acid. Maydica 2003, 48:75-84.

Krakowsky $\mathrm{M}$, Lee $\mathrm{M}$, Beeghly $\mathrm{H}$, Coors J: Characterization of quantitative trait loci affecting fiber and lignin in maize (Zea mays L.). Maydica 2003, 48(4):283-292. 
26. Krakowsky $M D$, Lee $M$, Coors JG: Quantitative trait loci for cell-wall components in recombinant inbred lines of maize (Zea mays L.) I: stalk tissue. Theor Appl Genet 2005, 111(2):337-346.

27. Krakowsky MD, Lee M, Coors JG: Quantitative trait loci for cell wall components in

28. Barrière $Y$, Riboulet $C$, Méchin $V$, Maltese $S$, Pichon $M$, Cardinal $A$, Lapierre $C$, Lubberstedt $T$, Martinant J-P: Genetics and genomics of lignification in grass cell walls based on maize as model species. Genes Genomes Genomics 2007, 1:133-156.

30. Barrière $\mathrm{Y}$, Thomas J, Denoue D: QTL mapping for lignin content, lignin monomeric

31. Truntzler M, Barriere Y, Sawkins MC, Lespinasse D, Betran J, Charcosset A, Moreau L: Meta-

35. Yan J, Yang X, Shah T, Sánchez-Villeda H, Li J, Warburton M, Yi Z, Crouch JH, Xu Y: Highthroughput SNP genotyping with the GoldenGate assay in maize. Mol Breeding 2010,

37. Taylor J, Butler D: R Package ASMap: Efficient Genetic Linkage Map Construction and Diagnosis. Journal of Statistical Software 2017, 079(6). 25(3):441-451.

Purcell S, Neale B, Toddbrown K, Thomas L, Ferreira MAR, Bender D, Maller J, Sklar P, Bakker PIWD, Daly MJ: PLINK: A tool set for whole-genome association and population-based linkage analyses. Am J Hum Genet 2007, 81(3):559-575. Liu X, Hu X, Li K, Liu Z, Wu Y, Wang H, Huang C: Genetic mapping and genomic selection for maize stalk strength. BMC Plant Biol 2020, 20(1):196.

504 42. Mechin V, Argillier O, Menanteau V, Barriere Y, Mila I, Pollet B, Lapierre C: Relationship of cell 
wall composition to in vitro cell wall digestibility of maize inbred line stems. Journal of the Science of Food \& Agriculture 2000, 80(5):574-580.

43. Lübberstedt T, Melchinger AE, Fähr S, Klein D, Dally A, Westhoff P: QTL mapping in testcrosses of flint lines of maize: III. Comparison across populations for forage traits. Crop Sci 1998, 38(5):1278-1289.

44. Barrière $Y$, Méchin V, Denoue D, Bauland C, Laborde J: QTL for yield, earliness, and cell wall quality traits in topcross experiments of the F838x F286 early maize RIL progeny. Crop Sci 2010, 50(5):1761-1772.

45. MaizeSequence [ http://ensembl.gramene.org/Zea_mays/Info/Index]

\section{Declarations}

\section{Ethics approval and consent to participate}

Not applicable

\section{Consent for publication}

Not applicable

\section{Availability of data and material}

The datasets supporting the conclusions of this article are included within the article and its additional files.

\section{Competing interests}

The authors declare that they have no competing interests.

\section{Funding}

This research was supported by the National Key Research and Development Program of China (Grant No. 2016YFD0101200), the National Natural Science Foundation of

27 China (Grant No. 31801367), and the Agricultural Science and Technology Innovation 528 Program at CAAS. 


\section{Authors' contributions}

$530 \mathrm{XY}$ carried out the experiments and analyzed the data, KL analyzed the data and wrote

531 the manuscript; XL constructed a genetic map for QTL mapping; XH, FM, QW, YW,

532 and SL assisted in data collection and field experiment; ZL and HW constructed the

533 RIL population and helped revise the manuscript; ZL, HW, and $\mathrm{CH}$ conceived and

534 designed the study. All authors have read and approved this manuscript.

\section{Acknowledgements}

536 not applicable 
539 Figure 1. Changes in cell wall components and digestibility traits after silking in a

540 recombinant inbred line (RIL) population. ADF, acid detergent fiber; ADL, acid

541 detergent lignin; CEL, cellulose; NDF, neutral detergent fiber; IVDMD, in vitro dry

542 matter digestibility. I-V represent 10-50 days after silking, respectively.

543 Figure 2. Correlation coefficients among acid detergent fiber (ADF), neutral

544 detergent fiber (NDF), cellulose (CEL), acid detergent lignin (ADL), and in vitro

545 dry matter digestibility (IVDMD) across five stages.

546 Figure 3. Chromosomal locations of quantitative trail loci (QTL) for cell wall

547 components and digestibility traits in a maize recombinant inbred line (RIL)

548 population. 


\section{Tables}

551 Table 1. Phenotypic values of cell wall components and digestibility traits at different developmental stages in a maize recombinant inbred 552 line (RIL) population

\begin{tabular}{|c|c|c|c|c|c|c|c|}
\hline \multirow{2}{*}{ Trait } & \multirow{2}{*}{ Type } & & \multicolumn{5}{|c|}{ Stage } \\
\hline & & & I & II & III & IV & $\mathrm{V}$ \\
\hline \multirow{5}{*}{$\mathrm{ADF}$} & Zheng58 & Mean & 24.46 & 24.86 & 32.67 & 40.96 & 30.89 \\
\hline & HD568 & Mean & 27.49 & 23.58 & 29.15 & 35.29 & 33.16 \\
\hline & \multirow{3}{*}{ RIL } & Mean $\pm \mathrm{SD}$ & $35.34 \pm 2.45$ & $34.73 \pm 2.78$ & $38.94 \pm 5.30$ & $43.69 \pm 5.16$ & $43.16 \pm 1.72$ \\
\hline & & Range & $27.90-41.86$ & $26.63-44.14$ & $28.57-54.76$ & $32.02-55.70$ & $37.96-48.77$ \\
\hline & & $H^{2}$ & 0.72 & 0.56 & 0.64 & 0.59 & 0.49 \\
\hline \multirow{5}{*}{ CEL } & Zheng58 & Mean & 21.3 & 22.93 & 29.2 & 36.98 & 28.17 \\
\hline & HD568 & Mean & 23.5 & 21.82 & 25.97 & 33.13 & 29.3 \\
\hline & \multirow{3}{*}{ RIL } & Mean \pm SD & $25.07 \pm 1.87$ & $25.16 \pm 1.91$ & $27.61 \pm 3.04$ & $30.11 \pm 2.57$ & $29.3 \pm 1.35$ \\
\hline & & Range & $19.53-28.64$ & $19.72-31.33$ & $19.82-36.02$ & $22.38-36.52$ & $25.13-33.26$ \\
\hline & & $H^{2}$ & 0.72 & 0.56 & 0.61 & 0.49 & 0.52 \\
\hline \multirow{5}{*}{ IVDMD } & Zheng58 & Mean & 71.68 & 71.2 & 52.87 & 33.55 & 52.88 \\
\hline & HD568 & Mean & 63.63 & 71.23 & 63.75 & 46.47 & 46.26 \\
\hline & \multirow{3}{*}{ RIL } & Mean \pm SD & $59.56 \pm 3.43$ & $58.70 \pm 3.55$ & $52.63 \pm 6.92$ & $47.49 \pm 6.90$ & $50.27 \pm 2.61$ \\
\hline & & Range & $49.40-69.90$ & $47.52-66.42$ & $34.52-66.98$ & $32.74-63.64$ & $41.97-57.54$ \\
\hline & & $H^{2}$ & 0.63 & 0.52 & 0.67 & 0.62 & 0.47 \\
\hline \multirow{2}{*}{$\mathrm{ADL}$} & Zheng58 & Mean & 6.47 & 6.85 & 7.64 & 8.57 & 7.62 \\
\hline & HD568 & Mean & 7.02 & 6.56 & 7.72 & 8.32 & 7.54 \\
\hline
\end{tabular}




\begin{tabular}{rrlrrrrr} 
& & Mean \pm SD & $7.50 \pm 0.38$ & $7.58 \pm 0.41$ & $7.75 \pm 0.54$ & $8.16 \pm 0.51$ & $8.00 \pm 0.28$ \\
& \multirow{2}{*}{ RIL } & Range & $5.93-8.35$ & $6.46-8.70$ & $6.23-9.27$ & $6.82-9.43$ & $7.03-8.84$ \\
& & $H^{2}$ & 0.78 & 0.56 & 0.66 & 0.62 & 70.55 \\
\multirow{4}{*}{ NDF } & Zheng58 & Mean & 49.85 & 48.37 & 59.93 & 54.94 \\
& HD568 & Mean & 52.36 & 48.53 & 53.13 & 50.58 & 57.54 \\
& & Mean \pm SD & $51.78 \pm 3.22$ & $51.18 \pm 3.32$ & $56.88 \pm 6.47$ & $62.00 \pm 6.49$ & $61.98 \pm 2.11$ \\
& \multirow{2}{*}{ RIL } & Range & $43.37-60.55$ & $41.84-62.88$ & $44.87-76.85$ & $47.6-76.96$ & $56.69-68.62$ \\
& & $H^{2}$ & 0.68 & 0.48 & 0.64 & 0.56 \\
\hline
\end{tabular}

$553 \quad H^{2}$ Broad-sense heritability. 
Table 2. Unconditional consensus quantitative trail loci (QTL) underlying cell wall components and digestibility traits at different stages

\begin{tabular}{|c|c|c|c|c|c|c|c|c|}
\hline QTL & $\mathrm{Chr}^{\mathrm{a}}$ & Bin & Peak $^{\mathrm{b}}$ & The closest marker & $\mathrm{CI}^{\mathrm{c}}$ & LOD & $\mathrm{PVE}^{\mathrm{d}}$ & Add. $^{\mathrm{e}}$ \\
\hline ADF_I_1 & 1 & 1.08 & 201.54 & lmk297 & 198.74-206.06 & 4.30 & 6.67 & 0.64 \\
\hline ADF_I_2 & 2 & 2.04 & 90.56 & $\operatorname{lmk} 522$ & 85.63-94.68 & 8.96 & 13.48 & -0.91 \\
\hline ADF_I_7 & 7 & 7.03 & 66.66 & $\operatorname{lmk} 1667$ & $62.88-70.94$ & 5.24 & 6.16 & 0.62 \\
\hline ADF_I_9 & 9 & 9.03 & 42.56 & $\operatorname{lmk} 1992$ & $40.7-47.16$ & 9.09 & 10.57 & 0.81 \\
\hline ADF_II_1 & 1 & 1.08 & 202.65 & lmk299 & 200.49-206.06 & 5.89 & 7.01 & 0.73 \\
\hline ADF_II_2 & 2 & 2.04 & 91.12 & $\operatorname{lmk} 523$ & $85.63-94.68$ & 7.52 & 12.13 & -0.97 \\
\hline ADF_II_8 & 8 & 8.05 & 63.19 & $\operatorname{lmk} 1844$ & $58.77-66.23$ & 5.15 & 6.61 & 0.72 \\
\hline ADF_III_2 & 2 & 2.04 & 92.83 & $\operatorname{lmk} 525$ & $89.26-96.56$ & 5.56 & 5.45 & -1.24 \\
\hline ADF_III_7 & 7 & 7.03 & 62.64 & $\operatorname{lmk} 1661$ & 58.97-66.66 & 4.95 & 5.70 & 1.27 \\
\hline ADF_IV_1 & 1 & 1.08 & 207.82 & lmk309 & 203.91-211.34 & 5.92 & 6.26 & 1.29 \\
\hline ADF_IV_4 & 4 & 4.03 & 12.30 & $\operatorname{lmk} 981$ & $8.45-17.95$ & 4.03 & 5.20 & 1.18 \\
\hline ADF_V_1 & 1 & 1.03 & 59.45 & $\operatorname{lmk} 80$ & 58.41-66.45 & 4.18 & 6.69 & 0.44 \\
\hline ADF_V_2 & 2 & 2.07 & 138.80 & $\operatorname{lmk} 588$ & $134.51-143.69$ & 6.60 & 8.45 & -0.51 \\
\hline ADF_V_9 & 9 & 9.03 & 45.24 & lmk1999 & $40.7-49.86$ & 4.30 & 8.04 & 0.49 \\
\hline ADL_I_1 & 1 & 1.08 & 201.33 & $\operatorname{lmk} 296$ & 200.49-207.16 & 6.62 & 7.70 & 0.11 \\
\hline ADL_I_2 & 2 & 2.07 & 140.76 & lmk593 & $137.14-143.69$ & 16.73 & 24.04 & -0.19 \\
\hline ADL_I_6 & 6 & 6.01 & 20.68 & $\operatorname{lmk} 1431$ & $17.85-21.34$ & 5.49 & 7.23 & 0.10 \\
\hline ADL_II_1 & 1 & 1.09 & 229.47 & $\operatorname{lmk} 338$ & $225.93-233.4$ & 5.31 & 6.88 & 0.11 \\
\hline ADL_II_2 & 2 & 2.07 & 141.24 & $\operatorname{lmk} 594$ & $139.07-143.69$ & 8.99 & 15.18 & -0.16 \\
\hline ADL_II_6 & 6 & 6.01 & 20.68 & $\operatorname{lmk} 1431$ & $17.85-22.57$ & 5.54 & 8.68 & 0.12 \\
\hline ADL_III_2 & 2 & 2.04 & 83.60 & $\operatorname{lmk} 514$ & $80.7-87.83$ & 7.04 & 7.13 & -0.14 \\
\hline
\end{tabular}




\begin{tabular}{|c|c|c|c|c|c|c|c|c|}
\hline ADL_III_6 & 6 & 6.01 & 14.47 & $\operatorname{lmk} 1419$ & $11.52-17.85$ & 5.81 & 7.72 & 0.15 \\
\hline ADL_III_7 & 7 & 7.03 & 67.52 & $\operatorname{lmk} 1668$ & $63.82-70.94$ & 4.10 & 4.26 & 0.11 \\
\hline ADL_IV_1 & 1 & 1.08 & 207.82 & lmk309 & $204.85-214.26$ & 4.59 & 6.39 & 0.13 \\
\hline ADL_V_2 & 2 & 2.07 & 141.24 & lmk594 & $137.86-144.65$ & 12.08 & 16.11 & -0.11 \\
\hline ADL_V_6 & 6 & 6.01 & 21.34 & $\operatorname{lmk} 1433$ & $19.17-25.26$ & 5.55 & 7.07 & 0.07 \\
\hline CEL_I_1 & 1 & 1.09 & 232.92 & lmk346 & $229.11-234.6$ & 5.21 & 6.32 & 0.47 \\
\hline CEL_I_2 & 2 & 2.04 & 91.12 & $1 \mathrm{mk} 523$ & $85.63-95.63$ & 4.94 & 9.21 & -0.81 \\
\hline CEL_I_2 & 2 & 2.07 & 140.76 & lmk593 & 139.07-143.69 & 5.45 & 13.82 & -0.90 \\
\hline CEL_I_6 & 6 & 6.01 & 20.68 & lmk1431 & $17.85-24.33$ & 5.57 & 7.24 & 0.50 \\
\hline CEL_II_2 & 2 & 2.04 & 91.12 & $\operatorname{lmk} 523$ & $85.63-94.68$ & 5.34 & 18.97 & -0.83 \\
\hline CEL_III_2 & 2 & 2.04 & 91.12 & $1 \mathrm{mk} 523$ & $87.83-95.63$ & 6.03 & 7.52 & -0.84 \\
\hline CEL_III_7 & 7 & 7.03 & 62.64 & $\operatorname{lmk} 1661$ & $58.97-66.66$ & 5.70 & 6.15 & 0.76 \\
\hline CEL_IV_2 & 2 & 2.04 & 92.83 & $\operatorname{lmk} 525$ & $89.26-96.56$ & 4.28 & 5.42 & -0.60 \\
\hline CEL_V_1 & 1 & 1.03 & 62.79 & $\operatorname{lmk} 87$ & $58.41-66.45$ & 6.36 & 8.63 & 0.40 \\
\hline CEL_V_1 & 1 & 1.08 & 202.65 & lmk299 & 200.49-206.06 & 4.22 & 5.12 & 0.21 \\
\hline CEL_V_2 & 2 & 2.07 & 136.78 & $1 \mathrm{mk} 583$ & $135.34-140.76$ & 10.46 & 16.88 & -0.56 \\
\hline IVDMD_I_2 & 2 & 2.04 & 91.96 & $1 \mathrm{mk} 524$ & 85.63-94.68 & 4.94 & 7.77 & 0.97 \\
\hline IVDMD_I_7 & 7 & 7.03 & 71.42 & $\operatorname{lmk} 1676$ & 68.99-77.63 & 5.46 & 5.71 & -0.82 \\
\hline IVDMD_I_9 & 9 & 9.03 & 43.07 & $\operatorname{lmk} 1994$ & $40.7-46.92$ & 11.18 & 13.53 & -1.28 \\
\hline IVDMD_I_10 & 10 & 10.07 & 49.46 & $\operatorname{lmk} 2120$ & $48.72-50.17$ & 5.64 & 5.07 & 0.79 \\
\hline IVDMD_II_1 & 1 & 1.08 & 202.65 & $\operatorname{lmk} 299$ & 200.13-206.06 & 6.26 & 6.66 & -0.92 \\
\hline IVDMD_II_2 & 2 & 2.04 & 92.83 & $\operatorname{lmk} 525$ & $89.26-96.56$ & 6.16 & 7.13 & 0.97 \\
\hline IVDMD_II_4 & 4 & 4.05 & 30.98 & $\operatorname{lmk} 1014$ & $26.63-34.83$ & 4.40 & 4.69 & -0.78 \\
\hline IVDMD_II_8 & 8 & 8.05 & 63.55 & $\operatorname{lmk} 1845$ & $58.77-66.23$ & 7.40 & 9.43 & -1.10 \\
\hline IVDMD_II_9 & 9 & 9.03 & 44.52 & lmk1997 & $40.7-46.92$ & 4.48 & 6.35 & -0.90 \\
\hline
\end{tabular}




\begin{tabular}{|c|c|c|c|c|c|c|c|c|}
\hline IVDMD_III_1 & 1 & 1.08 & 205.33 & $\operatorname{lmk} 305$ & $201.54-209.07$ & 8.07 & 12.98 & -2.53 \\
\hline IVDMD_III_2 & 2 & 2.04 & 92.83 & $1 \mathrm{mk} 525$ & 91.12-98.23 & 6.35 & 4.55 & 1.48 \\
\hline IVDMD_III_5 & 5 & 5.02 & 32.93 & $\operatorname{lmk} 1189$ & $28.74-39.46$ & 4.22 & 5.75 & 1.67 \\
\hline IVDMD_III_7 & 7 & 7.03 & 62.64 & $\operatorname{lmk} 1661$ & $58.97-66.66$ & 6.01 & 8.11 & -1.99 \\
\hline IVDMD_IV_1 & 1 & 1.08 & 207.82 & lmk309 & 203.91-211.34 & 7.19 & 6.76 & -1.79 \\
\hline IVDMD_V_1 & 1 & 1.08 & 203.45 & $1 \mathrm{mk} 301$ & 201.54-207.16 & 4.15 & 5.81 & -0.63 \\
\hline IVDMD_V_2 & 2 & 2.05 & 106.49 & $\operatorname{lmk} 539$ & $102.91-110.58$ & 4.25 & 4.69 & 0.57 \\
\hline IVDMD_V_8 & 8 & 8.05 & 58.28 & $\operatorname{lmk} 1828$ & $52.91-61.39$ & 4.09 & 4.80 & -0.58 \\
\hline IVDMD_V_9 & 9 & 9.03 & 45.96 & $1 \mathrm{mk} 2000$ & $42.83-46.92$ & 7.33 & 9.33 & -0.81 \\
\hline IVDMD_V_10 & 10 & 10.07 & 50.17 & $\operatorname{lmk} 2121$ & $48.97-50.17$ & 7.37 & 8.16 & 0.76 \\
\hline NDF_I_1 & 1 & 1.08 & 203.45 & $\operatorname{lmk} 301$ & 201.54-206.06 & 5.13 & 5.77 & 0.78 \\
\hline NDF_I_2 & 2 & 2.04 & 90.56 & $1 \mathrm{mk} 522$ & 85.63-94.68 & 9.33 & 10.15 & -1.05 \\
\hline NDF_I_7 & 7 & 7.03 & 71.42 & $\operatorname{lmk} 1676$ & $68.99-75.22$ & 5.67 & 5.98 & 0.80 \\
\hline NDF_I_8 & 8 & 8.01 & 20.24 & $\operatorname{lmk} 1771$ & $17.84-23.76$ & 4.54 & 6.73 & 0.86 \\
\hline NDF_I_9 & 9 & 9.03 & 43.07 & $\operatorname{lmk} 1994$ & $40.7-46.92$ & 9.69 & 12.69 & 1.16 \\
\hline NDF_II_1 & 1 & 1.08 & 202.65 & $\operatorname{lmk} 299$ & 200.13-206.06 & 6.42 & 9.94 & 1.05 \\
\hline NDF_II_2 & 2 & 2.04 & 92.83 & $\operatorname{lmk} 525$ & $85.63-94.68$ & 7.99 & 13.97 & -1.25 \\
\hline NDF_II_7 & 7 & 7.03 & 67.52 & $\operatorname{lmk} 1668$ & $63.82-71.18$ & 4.22 & 3.48 & 0.63 \\
\hline NDF_II_8 & 8 & 8.05 & 63.19 & $\operatorname{lmk} 1844$ & $59.5-67.19$ & 6.08 & 7.32 & 0.91 \\
\hline NDF_III_1 & 1 & 1.08 & 202.65 & lmk299 & 198.13-203.2 & 6.96 & 10.65 & 2.12 \\
\hline NDF_III_2 & 2 & 2.04 & 91.12 & $\operatorname{lmk} 523$ & $89.26-96.56$ & 5.41 & 5.73 & -1.56 \\
\hline NDF_III_7 & 7 & 7.03 & 65.25 & $\operatorname{lmk} 1665$ & 58.97-66.66 & 5.54 & 6.63 & 1.68 \\
\hline NDF_IV_1 & 1 & 1.08 & 207.82 & lmk309 & $203.91-211.34$ & 7.34 & 7.10 & 1.72 \\
\hline NDF_V_1 & 1 & 1.08 & 202.65 & $\operatorname{lmk} 299$ & 200.49-205.33 & 4.55 & 6.65 & 0.55 \\
\hline NDF_V_2 & 2 & 2.06 & 129.27 & $\operatorname{lmk} 572$ & $126.27-132.58$ & 5.64 & 7.73 & -0.60 \\
\hline
\end{tabular}


$\mathrm{NDF}_{-} \mathrm{V}_{-} 9$

9

9.03

45.24

$\operatorname{lmk} 1999$

40.7-46.92

7.44

11.71

0.73

${ }^{a}$ Chromosome

557 b Peak genetic position with the greatest logarithm of odds (LOD).

$558 \quad \mathrm{c}$ The 1.5-LOD confidence interval (CI) of QTL.

559 d Phenotypic variation explained by the additive effects of the mapped QTL.

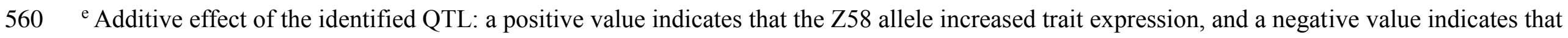
561 the HD568 allele increased expression. 
Table 3. Conditional consensus quantitative trail loci (QTL) underlying cell wall components and digestibility traits at different stages.

\begin{tabular}{|c|c|c|c|c|c|c|c|c|c|}
\hline Trait & QTL & $\mathrm{Chr}^{\mathrm{a}}$ & Bin & Peak $^{\mathrm{b}}$ & The closest marker & $\mathrm{CI}^{\mathrm{c}}$ & LOD & $\mathrm{PVE}^{\mathrm{d}}$ & $\mathrm{Add}^{\mathrm{e}}$ \\
\hline ADF_III|ADF_II & conqADF6 & 6 & 6.04 & 37.06 & $\operatorname{lmk} 1458$ & $33.02-40.98$ & 4.94 & 5.40 & 0.86 \\
\hline ADF_IV|ADF_III & conqADF1a & 1 & 1.04 & 103.67 & $\operatorname{lmk} 156$ & $101.98-107.31$ & 4.14 & 1.02 & 0.30 \\
\hline ADF_IV|ADF_III & conqADF3 & 3 & 3.03 & 21.8 & $\operatorname{lmk} 702$ & 18.09-25.4 & 4.32 & 3.89 & -0.58 \\
\hline ADF_V|ADF_IV & conqADF1b & 1 & 1.02 & 59.45 & $\operatorname{lmk} 80$ & $58.41-66.45$ & 8.11 & 10.15 & 0.52 \\
\hline ADF_V|ADF_IV & conqADF2 & 2 & 2.07 & 138.8 & $\operatorname{lmk} 588$ & $134.51-143.69$ & 5.69 & 11.99 & -0.56 \\
\hline ADL_III|ADL_II & conqADL10 & 10 & 10.06 & 37.16 & $\operatorname{lmk} 2097$ & $33.57-41.01$ & 4.41 & 4.84 & 0.08 \\
\hline ADL_IV|ADL_III & conqADL1a & 1 & 1.02 & 41.59 & $\operatorname{lmk} 59$ & $37.73-45.8$ & 5.08 & 5.34 & -0.06 \\
\hline ADL_V|ADL_IV & conqADL1b & 1 & 1.02 & 47.25 & $\operatorname{lmk} 68$ & $43.52-51.09$ & 4.84 & 7.98 & 0.07 \\
\hline ADL_V|ADL_IV & conqADL2 & 2 & 2.07 & 143.69 & $\operatorname{lmk} 595$ & $137.14-144.65$ & 6.73 & 13.41 & -0.09 \\
\hline CEL_III|CEL_II & conqCEL5 & 5 & 5.02 & 32.93 & $\operatorname{lmk} 1189$ & $28.74-37.06$ & 4.06 & 5.08 & -0.49 \\
\hline CEL_III|CEL_II & conqCEL7 & 7 & 7.03 & 62.64 & $\operatorname{lmk} 1661$ & $60.96-66.66$ & 6.96 & 5.43 & 0.51 \\
\hline CEL_IV|CEL_III & conqCEL1a & 1 & 1.02 & 41.59 & $\operatorname{lmk} 59$ & $37.73-45.8$ & 4.04 & 3.93 & -0.32 \\
\hline CEL_V|CEL_IV & conqCEL1b & 1 & 1.02 & 52.77 & $\operatorname{lmk} 74$ & $48.15-56.5$ & 9.25 & 10.70 & 0.41 \\
\hline CEL_V|CEL_IV & conqCEL2 & 2 & 2.07 & 136.78 & lmk583 & $132.95-140.76$ & 5.57 & 14.95 & -0.49 \\
\hline IVDMD_III|IVDMD_II & conqIVDMD1a & 1 & 1.10 & 232.92 & $\operatorname{lmk} 346$ & $230.98-234.6$ & 6.46 & 6.39 & -1.29 \\
\hline IVDMD_III|IVDMD_II & conqIVDMD2 & 2 & 2.07 & 151.59 & $\operatorname{lmk607}$ & $146.92-155.5$ & 5.05 & 6.06 & -1.25 \\
\hline IVDMD_III|IVDMD_II & conqIVDMD6 & 6 & 6.04 & 43.35 & $\operatorname{lmk} 1462$ & $37.06-47.26$ & 4.43 & 5.21 & -1.17 \\
\hline IVDMD_V|IVDMD_IV & conqIVDMD10 & 10 & 10.07 & 50.17 & $\operatorname{lmk} 2121$ & $46.8-50.17$ & 4.23 & 7.67 & 0.69 \\
\hline IVDMD_V|IVDMD_IV & conqIVDMD1b & 1 & 1.02 & 56.5 & $\operatorname{lmk} 77$ & $52.77-60.51$ & 6.23 & 8.68 & -0.72 \\
\hline IVDMD_V|IVDMD_IV & conqIVDMD9 & 9 & 9.02 & 28.05 & $\operatorname{lmk} 1957$ & $22.26-29.74$ & 5.61 & 9.08 & -0.74 \\
\hline NDF_III|NDF_II & conqNDF1a & 1 & 1.10 & 231.95 & $\operatorname{lmk} 342$ & $227.68-237.83$ & 5.42 & 6.24 & 1.16 \\
\hline NDF_III|NDF_II & conqNDF2a & 2 & 2.07 & 151.59 & $\operatorname{lmk607}$ & $146.92-154.25$ & 7.96 & 6.00 & 1.13 \\
\hline NDF_III|NDF_II & conqNDF6 & 6 & 6.04 & 46.06 & $\operatorname{lmk} 1463$ & $43.35-51.12$ & 4.32 & 5.82 & 1.13 \\
\hline
\end{tabular}




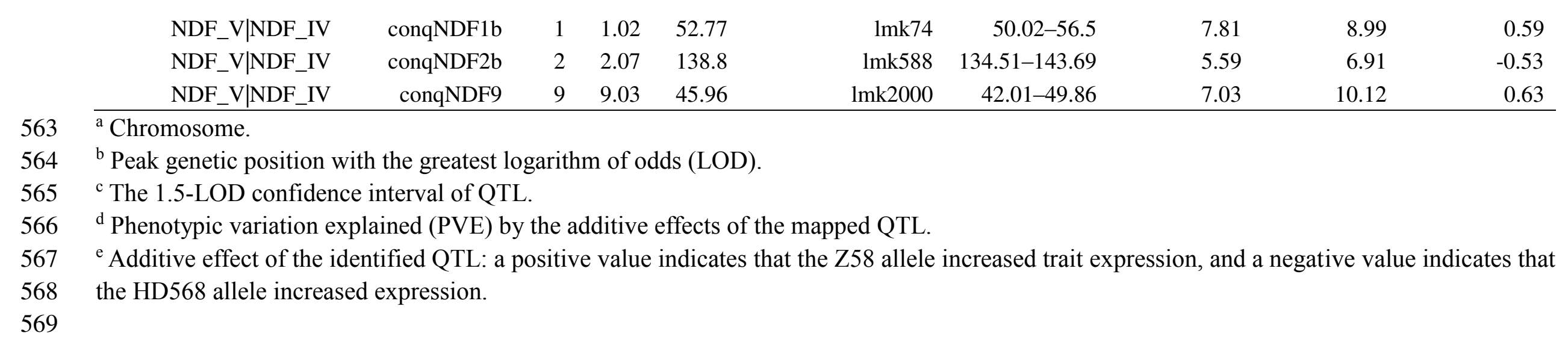

\section{Additional Files}

Additional file 3 Summary of broad sense heritability for five traits at each stage.

Additional file 4 Summary of analysis of variance for five traits at each stage. 
Figures
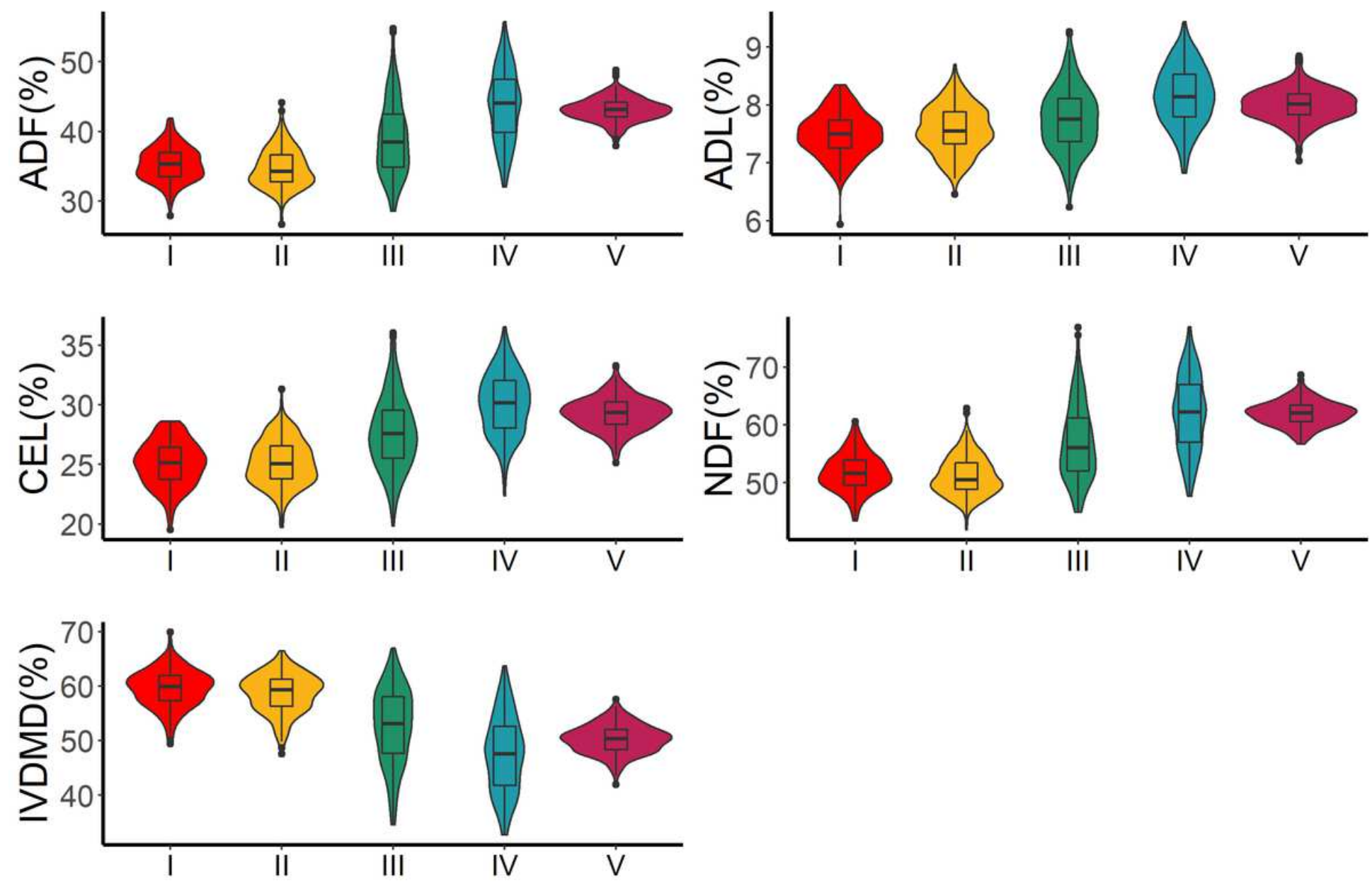

Figure 1

Changes in cell wall components and digestibility traits after silking in a recombinant inbred line (RIL) population. $A D F$, acid detergent fiber; $A D L$, acid detergent lignin; $C E L$, cellulose; NDF, neutral detergent fiber; IVDMD, in vitro dry matter digestibility. I-V represent 10-50 days after silking, respectively. 

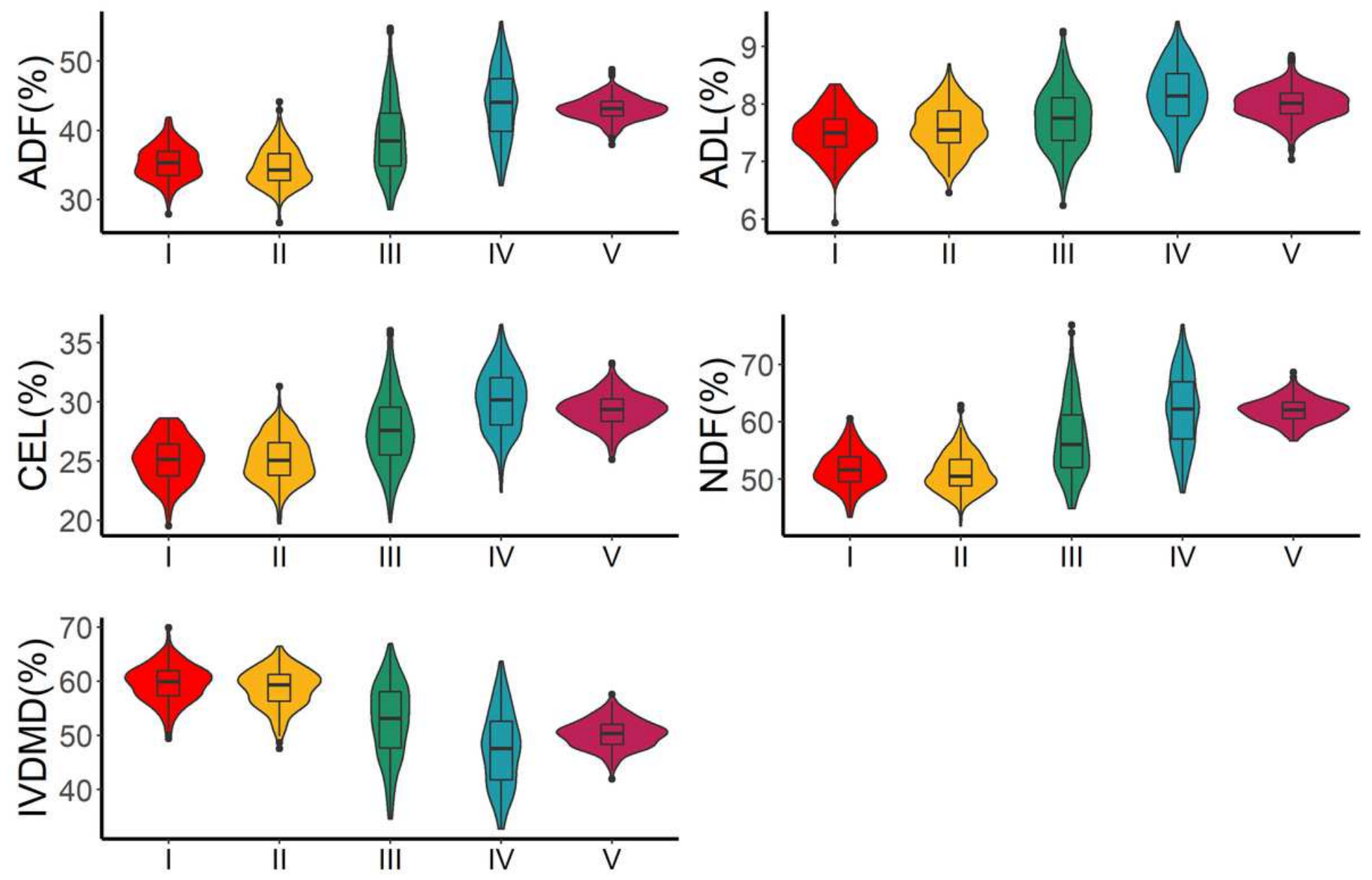

Figure 1

Changes in cell wall components and digestibility traits after silking in a recombinant inbred line (RIL) population. $A D F$, acid detergent fiber; $A D L$, acid detergent lignin; $C E L$, cellulose; NDF, neutral detergent fiber; IVDMD, in vitro dry matter digestibility. I-V represent 10-50 days after silking, respectively. 


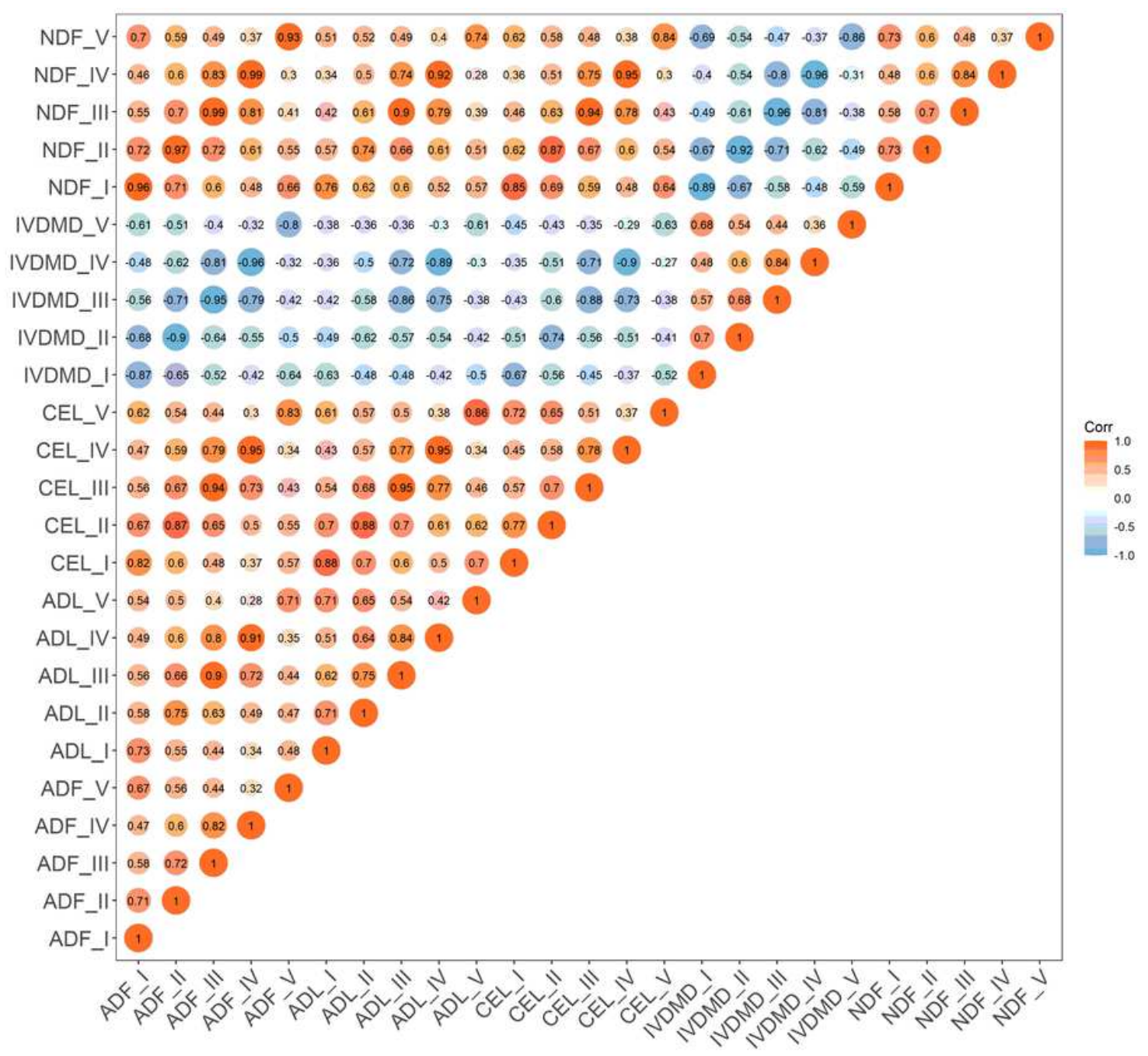

Figure 2

Correlation coefficients among acid detergent fiber (ADF), neutral detergent fiber (NDF), cellulose (CEL), acid detergent lignin (ADL), and in vitro dry matter digestibility (IVDMD) across five stages. 


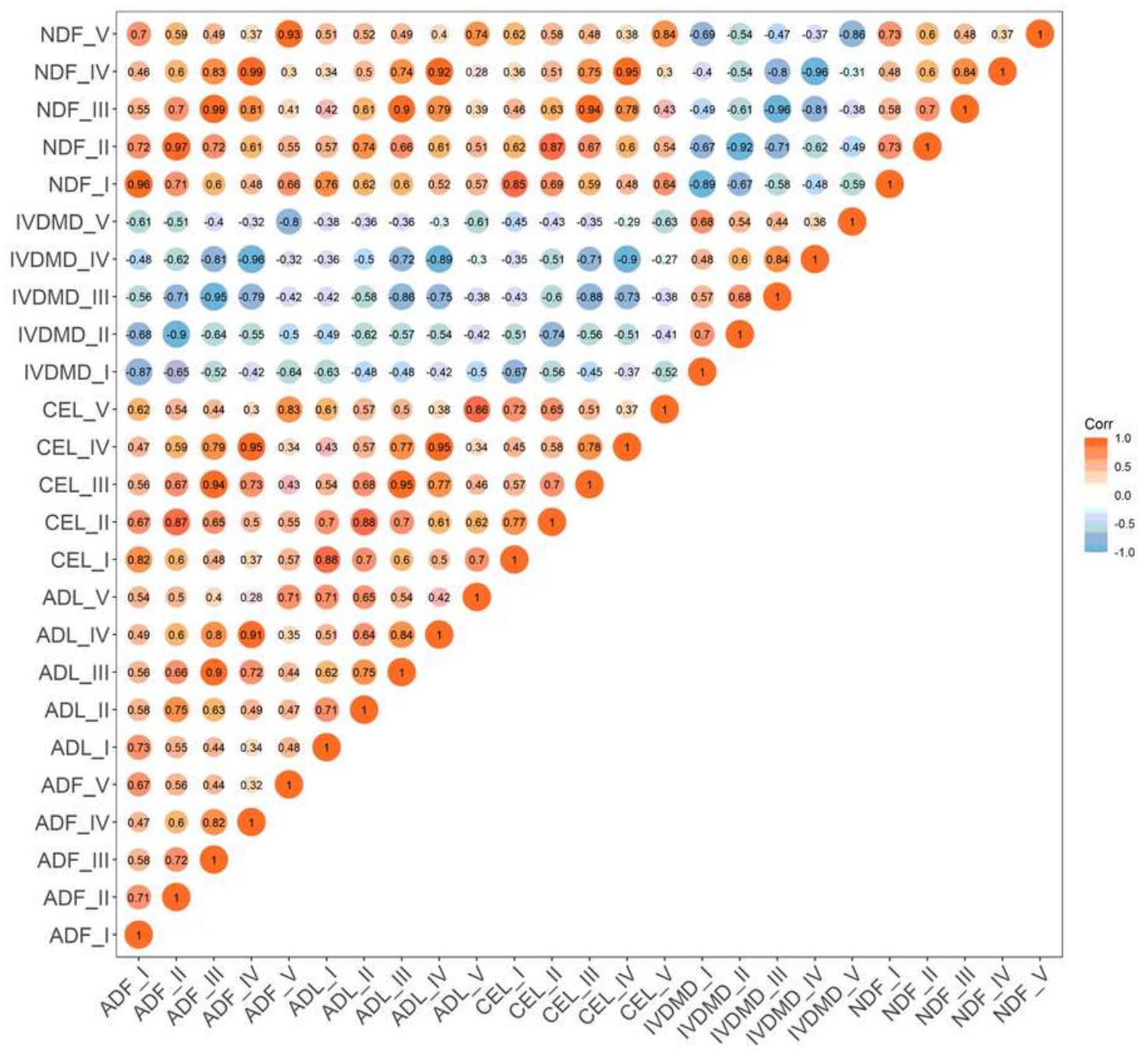

Figure 2

Correlation coefficients among acid detergent fiber (ADF), neutral detergent fiber (NDF), cellulose (CEL), acid detergent lignin (ADL), and in vitro dry matter digestibility (IVDMD) across five stages. 


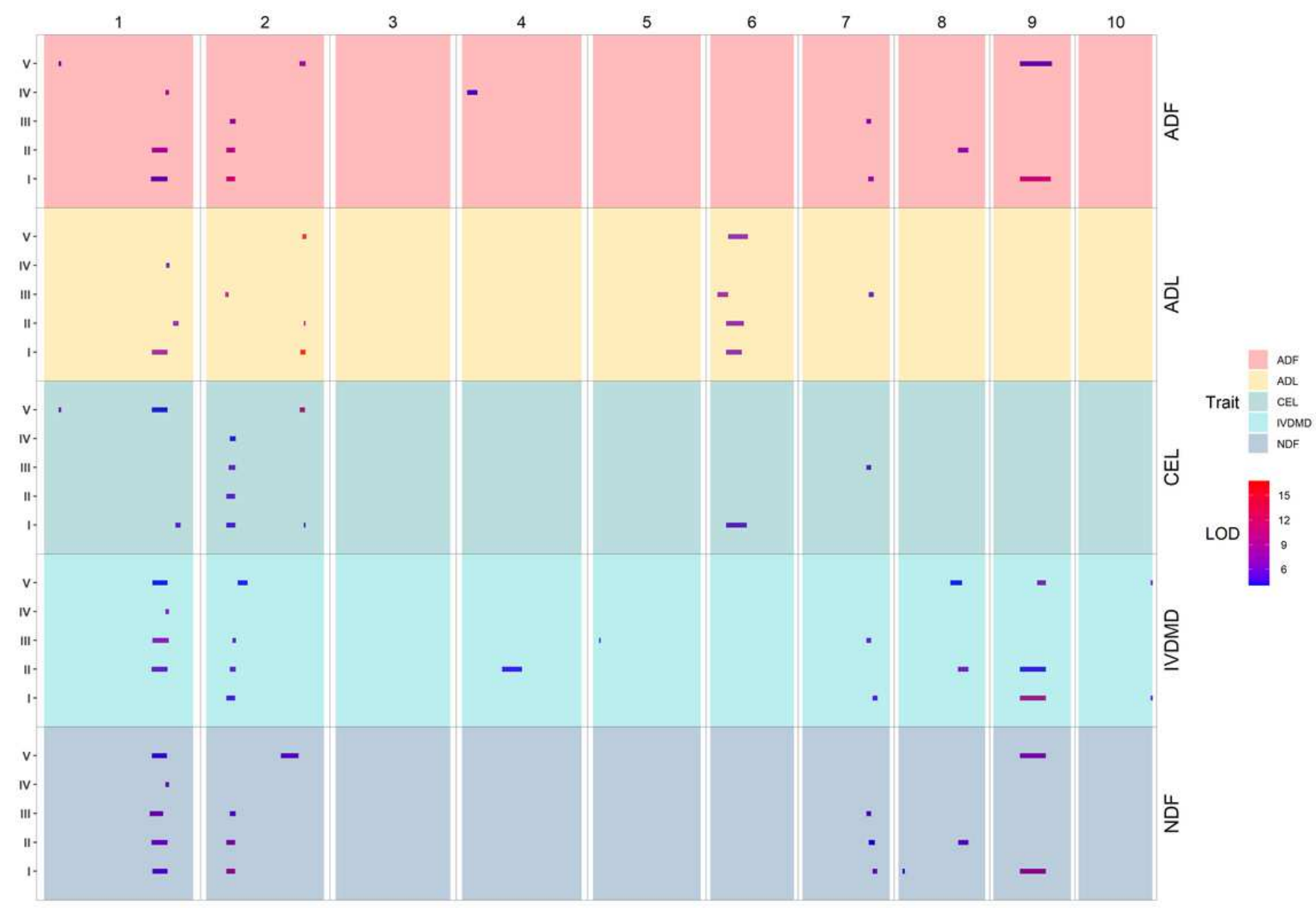

Figure 3

Chromosomal locations of quantitative trail loci (QTL) for cell wall components and digestibility traits in a maize recombinant inbred line (RIL) population. 


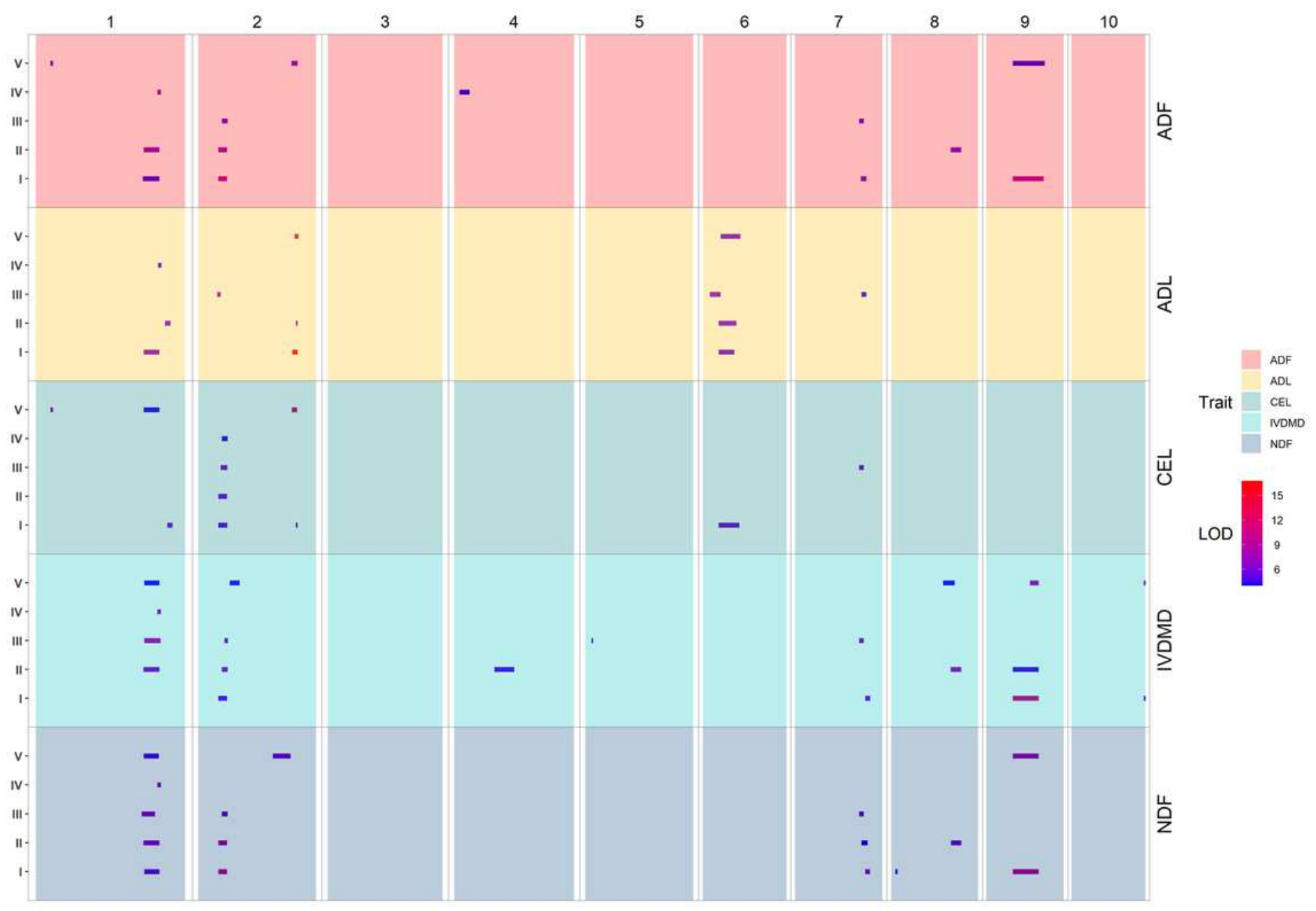

\section{Figure 3}

Chromosomal locations of quantitative trail loci (QTL) for cell wall components and digestibility traits in a maize recombinant inbred line (RIL) population.

\section{Supplementary Files}

This is a list of supplementary files associated with this preprint. Click to download.

- Additionalfile1.tif

- Additionalfile2.tif

- Additionalfile3.xlsx

- Additionalfile4.xIsx 